九州大学学術情報リポジトリ

Kyushu University Institutional Repository

\title{
Efficient levoglucosenone production by catalytic pyrolysis of cellulose mixed with ionic liquid
}

Kudo, Shinji

Research and Education Center of Carbon Resources, Kyushu University

Zhou, Zhenwei

Institute for Materials Chemistry and Engineering, Kyushu University

Norinaga, Koyo

Institute for Materials Chemistry and Engineering, Kyushu University

Hayashi, Jun-ichiro

Institute for Materials Chemistry and Engineering, Kyushu University

http://hdl. hand le. net/2324/25645

出版情報 : Green Chemistry. 13 (11)，pp.3306-3311，2011-11. Royal Society of Chemistry バージョン:

権利関係: (C) The Royal Society of Chemistry 


\title{
Efficient levoglucosenone production by catalytic pyrolysis of cellulose mixed with ionic liquid
}

\author{
Shinji Kudo, ${ }^{* a b}$ Zhenwei Zhou, ${ }^{a}$ Koyo Norinaga, ${ }^{a}$ and Jun-ichiro Hayashi ${ }^{a}$
}

Levoglucosenone is a synthetically valuable and versatile compound that is present as a minor product of cellulose pyrolysis. Here, we report the catalytic pyrolysis of cellulose by mixing with 1-butyl-2,3dimethylimidazolium triflate ionic liquid (IL), forming levoglucosenone in high yield. Catalysis of IL was selectively directed to form levoglucosenone, while the low content of IL (50\%) effectively prevented

10 formation of char, leading to a yield near $20 \%$ even at $250^{\circ} \mathrm{C}$. The thermally stable IL could be fully recovered from the mixture pyrolyzed up to $300^{\circ} \mathrm{C}$ and reutilized for pyrolysis.

\section{Introduction}

Due to the need for alternatives to fossil fuels, there is growing interest in renewable biomass as a source of fuels and fine 15 chemical products. Cellulose is one of the main components in biomass and is the most abundant organic substance on earth. The chemical structure of cellulose, consisting of a linear homopolymer of glucopyranose residues linked by $\beta-1,4$ glycosidic bonds, is well suited for the mass production of 20 monosaccharide derivatives. However, its utilization has been limited because it is chemically stabilized by an extensive network of intra- and inter-molecular hydrogen bonds.

Thermochemical processing, pyrolysis in particular, is the simplest way to convert cellulose into its degradation products.

${ }_{25}$ In this process, the progress of various reactions that occur in parallel and in series lead to a variety of products, such as anhydro-monosaccharides and furan derivatives. ${ }^{1,2}$ Levoglucosenone (1,6-anhydro-3,4-dideoxy- $\beta$-D-glycero-hex-3enopyranose-2-ulose) is one of the products from the pyrolysis of

30 cellulose. Due to its characteristic structure, having two chiral and six differently functionalized carbon atoms, levoglucosenone has been used as a chiral synthon for the synthesis of a variety of novel compounds (Scheme 1). ${ }^{3-6}$

Although the yield of levoglucosenone from cellulose 35 pyrolysis is very low even in the flash mode, ${ }^{1,7}$ an impregnation of phosphoric acid on/in the cellulose can catalyze pyrolysis for selective production, termed acid-catalyzed pyrolysis. ${ }^{8,9}$ Thus, many techniques, including flash pyrolysis ${ }^{10-12}$ and methods utilizing a solid acid catalyst, ${ }^{13}$ microwaves ${ }^{14}$ and a polar solvent 40 (sulfolane) with acid, ${ }^{15-17}$ have been developed to facilitate levoglucosenone production. Nevertheless, the conventional phosphoric acid-catalyzed method is the only viable approach in terms of process cost and convenience even with the low yield of no more than $10 \mathrm{wt} \%$ from cellulose, ${ }^{13,18}$ and therefore

45 levoglucosenone is still very expensive. Taking into account the issues associated with phosphoric acid, e.g., corrosion, water pollution, and insufficient recovery, ${ }^{13,19}$ a novel, green, and costeffective process is required to enable extensive utilization of levoglucosenone.

50 Ionic liquids (ILs) possess a variety of special properties including low vapor pressure and high thermal stability, and have attracted attention in cellulose-processing research. ${ }^{20}$ Since the pioneering research by Rogers et al., ${ }^{21}$ ILs have been used as "green" solvents for liquid-phase catalytic conversion of 55 cellulose into valuable chemicals e.g., 5-hydroxymethylfurfural and furfural. ${ }^{22-24}$ Despite an enormous amount of research, to our knowledge, there are only a few reports published on the direct use of ILs for the pyrolysis of cellulose or lignocellulosic biomass ${ }^{18,25}$ probably due to concerns about the thermal stability 60 of ILs at temperatures that are rarely examined $\left(>250^{\circ} \mathrm{C}\right)$. Therefore, ILs has been regarded only as solvents in most cellulose-processing studies.

In present work, 1-butyl-2,3-dimetylimidazolium ([BMMIM]) ILs were used as a catalyst for cellulose pyrolysis to produce ${ }_{65}$ levoglucosenone. With a similar or simpler production process as the phosphoric acid-catalyzed method, mixing a relatively small amount of ILs, especially [BMMIM] $\mathrm{CF}_{3} \mathrm{SO}_{3}$, with cellulose enabled the efficient production of levoglucosenone. Furthermore, the reutilization of ILs is discussed along with a 70 quantitative analysis of pyrolysis products.

\section{Experimental}

\section{Materials}

Microcrystalline cellulose (powder, Aldrich) was used as the cellulose sample with predrying in vacuo at ambient temperature. 75 The chemical composition, estimated by dry elemental analysis, was $44.3 \mathrm{wt} \% \mathrm{C}, 6.3 \mathrm{wt} \% \mathrm{H}, 49.4 \mathrm{wt} \% \mathrm{O}, 0.05 \mathrm{wt} \% \mathrm{~N}$, and < $0.01 \mathrm{wt} \%$ ash. The following ILs were used as-received without further purification: 1-butyl-3-methylimidazolium chloride ([BMIM]Cl) from Tokyo Chemical Industry (Japan), 1-butyl-2,3${ }_{80}$ dimethylimidazolium triflate ([BMMIM] $\mathrm{CF}_{3} \mathrm{SO}_{3}$ ) from IoLiTec Ionic Liquids Technologies GmbH (Germany), 1-butyl-2,3-

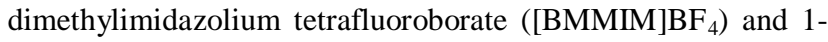
butyl-2,3-dimethylimidazolium hexafluorophosphate ([BMMIM]PF $\mathrm{PF}_{6}$ from Wako Pure Chemical Industries (Japan).

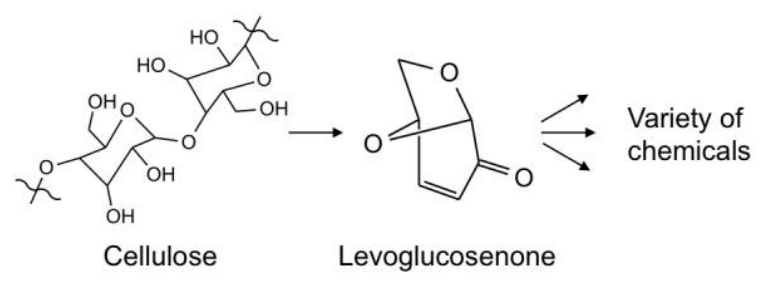

Scheme 1 
Levoglucosenone with a purity of $95.0 \%$, purchased from Toronto Research Chemicals (Canada), was used as a standard to determine the yield.

\section{Pyrolysis}

${ }_{5}$ Samples of mixtures of cellulose and IL were prepared by stirring in glass bottles for 15 min under ambient conditions at a ratio of 1:1 on a weight basis unless otherwise stated. The glass bottles were heated to $60^{\circ} \mathrm{C}$ on a hotplate when [BMMIM] $\mathrm{CF}_{3} \mathrm{SO}_{3}$ was used because its melting point is $41^{\circ} \mathrm{C}$.

${ }_{10}$ The mixture of levoglucosan with IL was also prepared in a similar manner. Cellulose impregnated with $3 \mathrm{wt} \%$ phosphoric acid (cellulose/PA) was prepared according to a published method. ${ }^{13}$

A glass tube reactor with an inner diameter of $20 \mathrm{~mm}$, 15 wrapped by a tape heater, was used to conduct the pyrolysis experiments. Samples of $1 \mathrm{~g}$ were placed on a quartz boat in the tube in contact with a thermocouple to control the temperature. The temperature of the sample was raised at a rate of $5^{\circ} \mathrm{C} \mathrm{min}{ }^{-1}$ and maintained at a given temperature for $20 \mathrm{~min}$ under 20 atmospheric pressure. The volatile products from pyrolysis were purged with a flow of helium (200 $\left.\mathrm{mL} \mathrm{min}^{-1}\right)$, and the condensable matter was collected in a series of two cold traps (kept at -30 and $-70^{\circ} \mathrm{C}, 50 \mathrm{~mL}$ each) and an aerosol filter located downstream of the reactor. The aerosol filter was essential for

25 capturing aerosol particles because $50-70 \%$ of the levoglucosenone was collected in this way. Non-condensable gases were collected with a gasbag for analysis by gas chromatography-flame ionization detection (GC-FID).

Thermogravimetric analysis (TGA) was also conducted to 30 determine the thermal stability of ILs and the weight change of the samples containing cellulose during pyrolysis using a Netzsch STA 449 F1.

\section{Analysis of pyrolysis products}

The condensable matter collected in cold traps and the aerosol 35 filter was recovered with methanol and subjected to the following analyses. Gas-chromatography-mass spectrometry (GC-MS; Shimadzu, QP-5000) was used for the qualitative identification of organic components using a capillary column: TC-1701 (14\% cyanopropylphenyl-86\% dimethylpolysiloxane, ${ }_{40} 60 \mathrm{~m}, 0.25 \mathrm{~mm}$ i.d., $0.25 \mu \mathrm{m}$ d.f.). The injector temperature was set to $345^{\circ} \mathrm{C}$, and the temperature profile of GC oven was $5 \mathrm{~min}$ at $40^{\circ} \mathrm{C}$; this was followed by a temperature increase of $4^{\circ} \mathrm{C} \mathrm{min}^{-1}$ until $250^{\circ} \mathrm{C}$ was reached and maintained for $20 \mathrm{~min}$. Assignments of the main peaks were made using mass spectral detection based 45 on the National Institute of Standards and Technology (NIST) MS library. Water content in the condensable matter was calculated by Karl-Fischer titration analysis using Kyoto Electronics, MKC-210. The yield of levoglucosenone was determined by high-performance liquid chromatography (HPLC) 50 on a Shimadzu LC-20 prominence series equipped with a photo diode array detector (Shimadzu, SPD-M20A) and Phenomenex Synergi Hydro-RP column $(100 \mathrm{~mm} \times 3.0 \mathrm{~mm}, 2.5 \mu \mathrm{m})$, with ultraviolet (UV) detection at $210 \mathrm{~nm}$. The mobile phase, 10 mmol L $\mathrm{L}^{-1}$ phosphate buffer solution, was supplied at a constant 55 flow rate of $1.0 \mathrm{~mL} \mathrm{~min}^{-1}$ and $40^{\circ} \mathrm{C}$. The concentration of levoglucosenone was calculated from the calibration curve using three concentrations of standard samples.

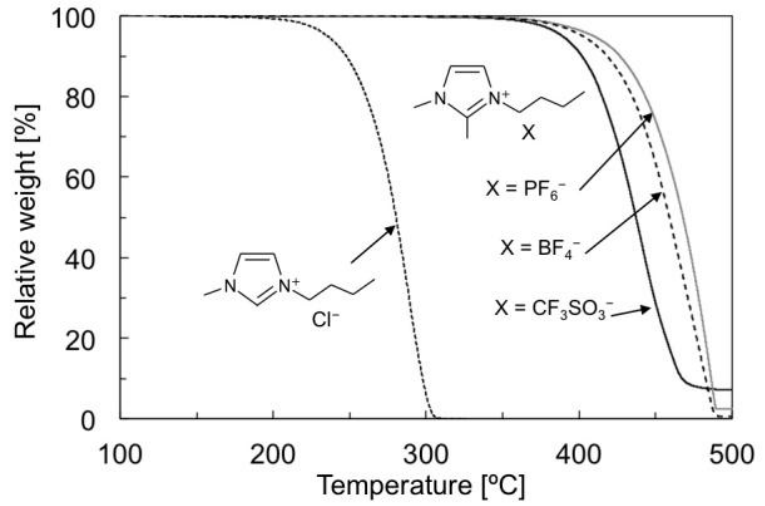

Fig. 1 Weight change curves of ILs ([BMIM]Cl, [BMMIM] $\mathrm{PF}_{6}, \mathrm{BF}_{4}$, 60 and $\mathrm{CF}_{3} \mathrm{SO}_{3}$ ): Initial sample mass $15 \mathrm{mg}, \mathrm{Ar} 70 \mathrm{~mL} \mathrm{~min}^{-1}$, heating rate $=$ $5^{\circ} \mathrm{C} \min ^{-1}$.

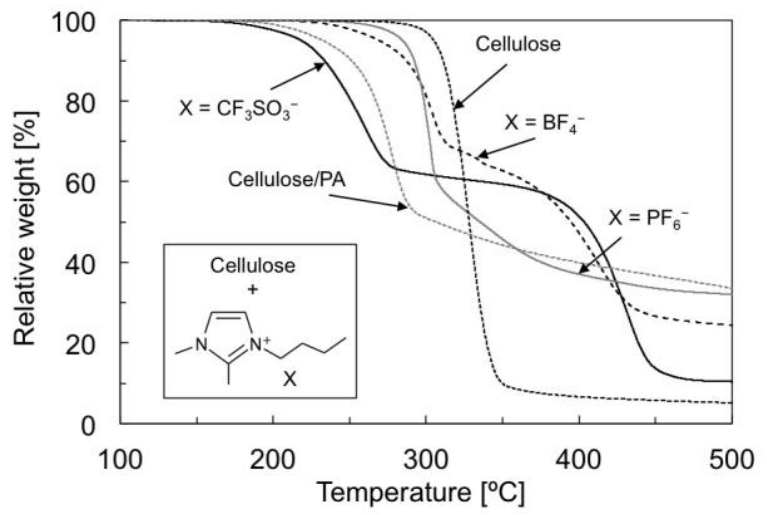

Fig. 2 Weight change curves of cellulose, cellulose/PA, and cellulose mixed with ILs at $1: 1$ on a weight basis during pyrolysis: Initial sample 65 mass $5 \mathrm{mg}$, Ar $70 \mathrm{~mL} \mathrm{~min}^{-1}$, heating rate $=5^{\circ} \mathrm{C} \mathrm{min}^{-1}$.

The solid residue from pyrolysis was suspended in ethanol, stirred overnight, filtered, and dried in vacuo at $50^{\circ} \mathrm{C}$. The resulting solid residue was defined as char, and the ethanol was removed to recover the $\mathrm{IL}$ using a rotary evaporator operated at ${ }_{70} 60^{\circ} \mathrm{C}$ and $175 \mathrm{mbar}$ for $5 \mathrm{~h}$. Part of the recovered $\mathrm{IL}$ was mixed with $\mathrm{CDCl}_{3}$ and analyzed by nuclear magnetic resonance $\left({ }^{1} \mathrm{H}\right.$ NMR) spectroscopy. The ${ }^{1} \mathrm{H}$ NMR spectra were recorded using a Jeol JNM-ECA (600 MHz) and tetramethylsilane as an internal standard.

\section{${ }_{75}$ Results and discussion}

\section{General}

Mixing with the IL caused swelling of cellulose, which was independent of IL type. The uniformity of the mixture was confirmed by repetitive TGA with random samplings. The 80 mixtures could be treated as a powder due to the low content of IL when the content was below $50 \mathrm{wt} \%$. In the case of $[\mathrm{BMMIM}] \mathrm{CF}_{3} \mathrm{SO}_{3}$, the char resulting from pyrolysis was also powder-like. In this way, the mixtures could be treated in pyrolysis tests as easily as non-treated cellulose.

\section{${ }_{85}$ Thermogravimetric analysis}

The thermal stability of IL is important for process safety and cost reduction by its reutilization. ILs used for cellulose pyrolysis, 1-butyl-2,3-dimethylimidazolium salts, are thermally stable up to 
Table 1 Product yields from pyrolysis.

\begin{tabular}{|c|c|c|c|c|c|c|c|c|}
\hline \multirow[b]{2}{*}{ Entry } & \multirow[b]{2}{*}{ Sample (content of IL in mixture, wt $\%$ ) } & \multirow[b]{2}{*}{$T_{\mathrm{P}}{ }^{a}\left[{ }^{\circ} \mathrm{C}\right]$} & \multicolumn{4}{|c|}{ Yield [wt $\%$ on a cellulose mass basis] } & \multirow[b]{2}{*}{$\begin{array}{l}\text {-Total mass } \\
\text { recovery [\%] }\end{array}$} & \multirow{2}{*}{$\begin{array}{l}\mathrm{IL} \text { recovery } \\
{[\%]}\end{array}$} \\
\hline & & & $\mathrm{CO} / \mathrm{CO}_{2}$ & $\begin{array}{l}\text { Condensable } \\
\text { matter }^{b} \text { (water) }\end{array}$ & Char $^{c}$ & $\begin{array}{l}\text { Levoglucosenone } \\
\left(\text { in mol } \%^{d} \text { ) }\right.\end{array}$ & & \\
\hline$\overline{1}$ & Cellulose & 350 & $0.8 / 2.8$ & $57.3(22.2)$ & 24.6 & $2.4(3.1)$ & $85.5^{e}$ & - \\
\hline 3 & Cellulose/[BMMIM]CF $\mathrm{CO}_{3}(50)$ & 250 & $0.1 / 0.4$ & $44.1(23.0)$ & 50.0 & $19.0(24.4)$ & 98.1 & 101.8 \\
\hline 4 & Cellulose/[BMMIM]CF $\mathrm{SO}_{3}(50)$ & 300 & $0.8 / 2.2$ & $62.0(32.0)$ & 32.7 & $21.4(27.6)$ & 98.6 & 99.4 \\
\hline 5 & Cellulose/[BMMIM] $\mathrm{CF}_{3} \mathrm{SO}_{3}(75)^{f}$ & 300 & $0.9 / 2.7$ & $52.3(36.3)$ & 45.2 & $9.8(12.6)$ & 100.1 & 100.1 \\
\hline 6 & Cellulose/[BMMIM] $\mathrm{CF}_{3} \mathrm{SO}_{3}(25)^{g}$ & 300 & $0.7 / 2.3$ & $55.6(31.6)$ & 40.5 & $17.2(22.1)$ & 99.3 & 99.8 \\
\hline 9 & Cellulose/[BMMIM]BF ${ }_{4}(50)$ & 300 & $0.9 / 4.8$ & $69.9(20.8)$ & 63.3 & n.d. ${ }^{h}$ & 98.4 & 78.6 \\
\hline 10 & Cellulose/[BMMIM]CF${ }_{3} \mathrm{SO}_{3}(50)^{i}$ & 300 & $0.8 / 2.4$ & $60.6(30.6)$ & 31.4 & $20.7(26.6)$ & 98.0 & 100.2 \\
\hline
\end{tabular}

${ }^{a}$ Final temperature for pyrolysis. ${ }^{b}$ Including all condensables collected in two cold traps and an aerosol filter. ${ }^{c}$ Char and recovered IL are defined as the solid and liquid products separated from the solid residue of pyrolysis by ethanol extraction, respectively. ${ }^{d}$ Molar yield of levoglucosenone per molar number of D-glucopyranose units calculated from weight of cellulose in sample. ${ }^{e}$ Low recovery rate resulted from tar deposition on the reactor wall. ${ }^{f, g}$ 5 Samples: 1.4 and $1.8 \mathrm{~g}$, respectively (the others: $1 \mathrm{~g}$ each). ${ }^{h}$ Not detected in HPLC analysis. ${ }^{i}$ Using $[\mathrm{BMMIM}] \mathrm{CF}_{3} \mathrm{SO}_{3}$ recovered from pyrolysis in entry 4.

$300^{\circ} \mathrm{C}$, as shown in the TGA results (Fig. 1), because alkyl substituent at the $\mathrm{C} 2$ position in 1-butyl-3-methylimidazolium generally stabilizes the cation against decomposition by shielding ${ }_{10}$ it from anion attack. ${ }^{26}$ This is evidenced by the comparatively low decomposition temperature of [BMIM]Cl, which is a prototypical IL used in cellulose-processing studies.

The [BMMIM]-type ILs are expected to show similar thermal stability even in the cellulose/IL mixture if they are not damaged 15 during cellulose pyrolysis. Weight change curves (Fig. 2) show that the thermal stability depends on the type of counterpart anion; only [BMMIM] $\mathrm{CF}_{3} \mathrm{SO}_{3}$ maintained its stability. In contrast to the monotonous weight loss of cellulose/[BMMIM] $\mathrm{PF}_{6}$, the mixtures with $[\mathrm{BMMIM}] \mathrm{BF}_{4}$ or $[\mathrm{BMMIM}] \mathrm{CF}_{3} \mathrm{SO}_{3}$ lost their 20 weight in two steps. The first weight loss (on the lower temperature side) was caused by the pyrolysis of cellulose, and the second one was primarily caused by decomposition of IL, although cellulose/[BMMIM] $\mathrm{BF}_{4}$ lost part of the $\mathrm{IL}$ during the former period (demonstrated by product analyzes in the following 25 sections). The isolation of temperature ranges for cellulose pyrolysis and $\mathrm{IL}$ decomposition strongly supports the possibility of IL reutilization.

More importantly, pyrolysis of cellulose in the mixture started at lower temperature than pure cellulose pyrolysis, indicating the 30 catalysis of ILs toward cellulose pyrolysis. Interestingly the catalytic effect was more significant following the order $\mathrm{CF}_{3} \mathrm{SO}_{3}$ $>\mathrm{BF}_{4}>\mathrm{PF}_{6}$, which was consistent with the order of $p \mathrm{~K}_{\mathrm{a}}$ of their conjugated acids and was also related to the properties of the ILs, such as the donor number and dielectric constants, regardless of 35 the cation type. ${ }^{20,27}$

The type of $\mathrm{IL}$ anion thus affected the onset temperature of cellulose pyrolysis. In a similar type of experiment using dicationic molten salt, Sheldrake and Schleck ${ }^{18}$ suggested that the reduction of the onset temperature was partially caused by a 40 direct interaction between the ILs and cellulose, such as its solvent power against cellulose. The solvent power is very important for the swelling of cellulose via breaking the intermolecular hydrogen-bond network, resulting in enhanced accessibility to the reaction center. Additionally, it is plausible 45 that the $\mathrm{IL}$ acted as a catalyst during pyrolysis, for protonating an oxygen atom on glycosidic bonds and splitting the polymer chain in a similar reaction pathway to that of phosphoric acid-catalyzed pyrolysis. The highest catalytic activity of [BMMIM] $\mathrm{CF}_{3} \mathrm{SO}_{3}$ is therefore considered to be derived from $\mathrm{CF}_{3} \mathrm{SO}_{3}{ }^{-}$, which is the

50 conjugated base of a superacid, trifluoromethanesulfonic acid $\left(H_{0}\right.$ $<-14)$.

By fitting the first-order reaction model to TGA data, the activation energy was calculated to be $94 \mathrm{~kJ} \mathrm{~mol}^{-1}\left(100-270^{\circ} \mathrm{C}\right)$ for cellulose/[BMMIM] $\mathrm{CF}_{3} \mathrm{SO}_{3}$, while $205\left(100-350^{\circ} \mathrm{C}\right)$ and 117 ${ }_{55} \mathrm{~kJ} \mathrm{~mol}^{-1}\left(100-280^{\circ} \mathrm{C}\right)$ for pure cellulose and cellulose/PA, respectively, suggesting a strong catalytic effect of the IL.

\section{Pyrolysis experiments}

The catalytic effect observed in the pyrolysis of cellulose/IL mixtures encouraged us to investigate the yield of the desired 60 product, levoglucosenone. The conventional phosphoric acidcatalyzed method contributes to the effective splitting of glycosidic bonds to selectively yield levoglucosenone. However, an inevitable acceleration of charring due to the condensation reaction limits the yield of organic volatiles, including ${ }_{65}$ levoglucosenone. ${ }^{19}$ This tendency becomes pronounced in a slow pyrolysis, in the sense of contrast to flash pyrolysis, and a char yield of $50 \mathrm{wt} \%$ at $300^{\circ} \mathrm{C}$ was obtained in this study (Table 1, entry 2).

Pyrolysis of cellulose/[BMMIM $] \mathrm{CF}_{3} \mathrm{SO}_{3}$ at $250^{\circ} \mathrm{C}$ produced 70 char and condensable matter at yields comparable to those from cellulose/PA, while forming water at a lower yield. Assuming that the water was a product of condensation leading to char formation, ${ }^{1}$ this indicates that the charring from cellulose/[BMMIM] $\mathrm{CF}_{3} \mathrm{SO}_{3}$ is less significant than that from 75 cellulose/PA at an equivalent conversion of cellulose. A higher temperature, $\quad 300^{\circ} \mathrm{C}$, for the pyrolysis of cellulose/[BMMIM] $\mathrm{CF}_{3} \mathrm{SO}_{3}$, therefore, resulted in a decrease in the char yield to $32.7 \mathrm{wt} \%$ with water content in condensable matter similar to that from cellulose/[BMMIM] $\mathrm{CF}_{3} \mathrm{SO}_{3}$ at $250^{\circ} \mathrm{C}$. ${ }_{80}$ Thus, the $[\mathrm{BMMIM}] \mathrm{CF}_{3} \mathrm{SO}_{3}$ catalyzed the low-temperature pyrolysis of cellulose, producing more condensable matter while preventing the formation of char.

The yields of levoglucosenone from [BMMIM] $\mathrm{CF}_{3} \mathrm{SO}_{3}$ were $19.0-22.0 \mathrm{wt} \%$ at $250-350^{\circ} \mathrm{C}$, which were more than double that 85 from cellulose/PA. This represents that $24.4-28.9 \%$ of $\mathrm{D}^{-}$ glucopyranose in cellulose was converted to levoglucosenone. The GC-MS chromatogram shown in Fig. 3 (c) confirms a high 

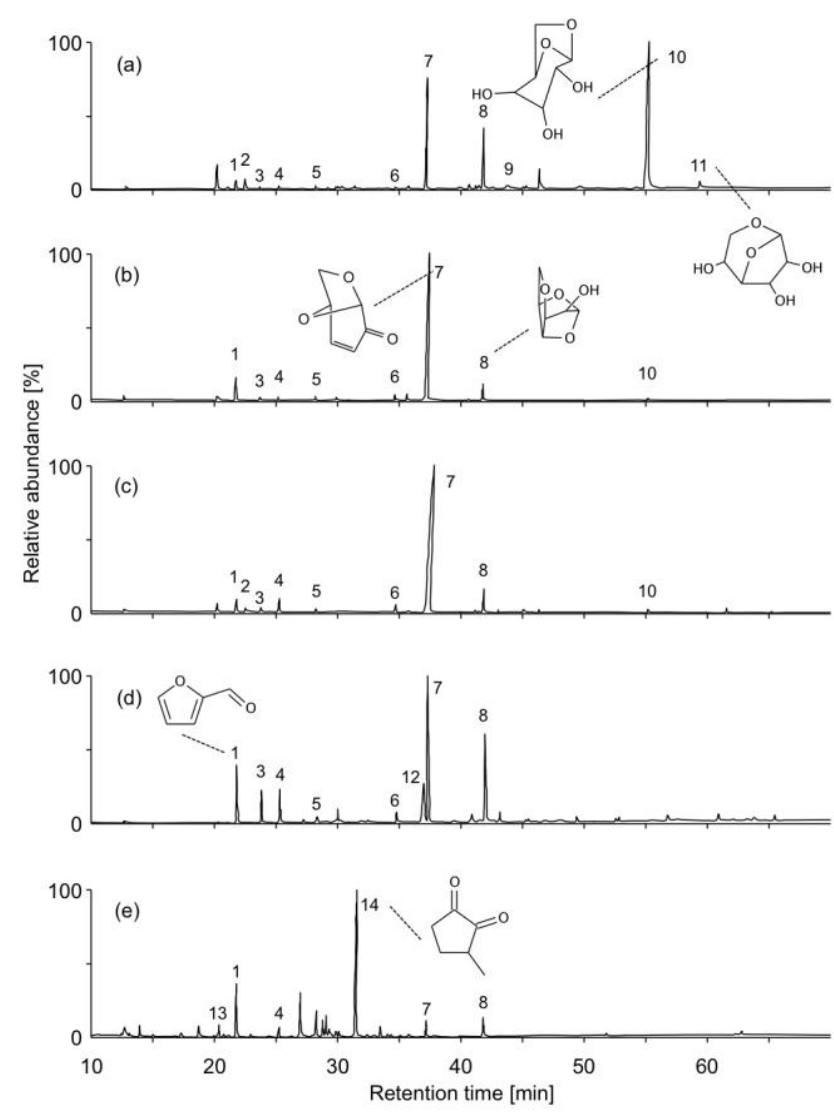

Fig. 3 GC-MS chromatograms of condensable matter from the $-30^{\circ} \mathrm{C}$ cold trap diluted with $3 \mathrm{~mL}$ of methanol obtained from pyrolysis of (a) cellulose at $350^{\circ} \mathrm{C}$, (b) cellulose $/ \mathrm{PA}$ at $300^{\circ} \mathrm{C}$, (c) cellulose/ 5 [BMMIM] $\mathrm{CF}_{3} \mathrm{SO}_{3}$ at $300^{\circ} \mathrm{C}$, (d) levoglucosan/[BMMIM]CF $\mathrm{CF}_{3} \mathrm{SO}_{3}$ at $300^{\circ} \mathrm{C}$, and (e) cellulose/[BMMIM]BF 4 at $300^{\circ} \mathrm{C}$. The main peaks are assigned as follows: 1: furfural, 2: 2-propylfuran, 3: $\alpha$-angelica lactone, 4: 2-acetylfuran, 5: 5-methylfurfural, 6: 2-furancarboxylic acid, 7: levoglucosenone, 8 : 1,4:3,6-dianhydro- $\alpha$-D-glucopyranose, $9: \quad 5$ 10 hydroxymethylfurfural, 10: levoglucosan, 11: 1,6-anhydro- $\beta$-Dglucofuranose, 12: acetic acid butyl ester, 13: 2,5-dimethoxytetrahydro furan, 14: 3-methyl-1,2-cyclopentanedione.

selectivity for levoglucosenone compared to the other products. In fact, the selectivity of levoglucosenone was $71.3 \mathrm{wt} \%$ at $300^{\circ} \mathrm{C}$ 15 for condensable matter, excluding water. The composition of GCMS-detectable condensable products from cellulose $/ \mathrm{CF}_{3} \mathrm{SO}_{3}$ was very similar to that from the cellulose/PA (Fig. 3 (b)). With levoglucosenone as a main product, the major by-products were levoglucosan, 1,4:3,6-dianhydro- $\alpha$-D-glucopyranose, and furan 20 derivatives.

It is commonly believed that the formation of levoglucosan is the first step of cellulose pyrolysis, followed by the formation of other anhydrosugars, including levoglucosenone $\left(-2 \mathrm{H}_{2} \mathrm{O}\right.$ from levoglucosan), and the anhydrosugars thermochemically degrade 25 to furanic derivatives. ${ }^{1}$ When mixed with $[\mathrm{BMMIM}] \mathrm{CF}_{3} \mathrm{SO}_{3}$ and pyrolyzed, levoglucosan was primarily converted to levoglucosenone (Fig. 3 (d)). However, the yield was only 6.5 wt $\%$ due to a relatively high yield of char and furan derivatives, which were derived from repolymerization and degradation of 30 anhydrosugars, respectively. The same tendency was observed during the pyrolysis of cellulose mixed with [BMMIM] $\mathrm{CF}_{3} \mathrm{SO}_{3}$ at a weight ratio of 1:3 (Table 1 , entry 5). These results suggest that an excess amount of IL compared with cellulose unfavorably
Table 2 Elemental composition of char from the pyrolysis of 35 cellulose/[BMMIM] $\mathrm{CF}_{3} \mathrm{SO}_{3}(50 \mathrm{wt} \%)$ at different temperatures, $T_{\mathrm{P}}$.

\begin{tabular}{lllll}
\hline \multicolumn{5}{l}{ Element, content [wt\%-dry] } \\
$T_{\mathrm{P}}\left[{ }^{\circ} \mathrm{C}\right]$ & $\mathrm{C}$ & $\mathrm{H}$ & $\mathrm{O}$ & $\mathrm{N}$ \\
\hline 250 & 54.1 & 4.9 & 40.7 & 0.3 \\
300 & 66.9 & 3.7 & 28.2 & 1.0 \\
350 & 69.1 & 3.4 & 25.4 & 1.6 \\
\hline
\end{tabular}

decelerates the diffusion of generated anhydrosugars, including levoglucosenone, into the gas phase, leading to their repolymerization and degradation.

40 On the other hand, the reduction in $\mathrm{IL}$ content in the mixture (25 wt\%) resulted in a slight decrease in the yield of levoglucosenone (Table 1, entry 6), probably due to the difficulty of full contact with cellulose.

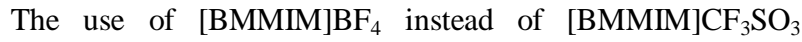
45 significantly altered the distribution of condensable products (Fig. 3(e)), producing little to no levoglucosenone, because it was not detected by HPLC analysis. Moreover, the recovery of $[\mathrm{BMMIM}] \mathrm{BF}_{4}$ was as low as $78 \%$ due to its decomposition and/or incorporation into the char matrix.

\section{${ }_{50}$ Reutilization of IL}

The IL, [BMMIM] $\mathrm{CF}_{3} \mathrm{SO}_{3}$, was thus found to be effective for the selective production of levoglucosenone at low temperatures. To explore the practical use of this, it is necessary to examine its reusability.

55 The original light yellow color of [BMMIM $] \mathrm{CF}_{3} \mathrm{SO}_{3}$ turned brown after the recovery from pyrolysis at $250^{\circ} \mathrm{C}$. The ${ }^{1} \mathrm{H}$ NMR analysis assigned the brown color to levoglucosenone remaining in $[\mathrm{BMMIM}] \mathrm{CF}_{3} \mathrm{SO}_{3}$ as an impurity at a concentration of less than $0.5 \mathrm{wt} \%$. On the other hand, the original color of

${ }_{60}[\mathrm{BMMIM}] \mathrm{CF}_{3} \mathrm{SO}_{3}$ was unchanged after pyrolysis at higher temperatures. Impurities were not detected via NMR analysis. Temperatures higher than $250^{\circ} \mathrm{C}$ were therefore necessary for complete evaporation of the pyrolysis products and regeneration of [BMMIM] $\mathrm{CF}_{3} \mathrm{SO}_{3}$. As seen in Table 1 (entries 4 and 10), the 65 twice-repeated use of the $\mathrm{IL}$ in the pyrolysis at $300^{\circ} \mathrm{C}$ reproduced the product distribution from cellulose. This is evidence that there was no or a negligible chemical change in $[\mathrm{BMMIM}] \mathrm{CF}_{3} \mathrm{SO}_{3}$ during the reaction process.

Table 2 presents the results of elemental analysis of chars 70 recovered from pyrolysis at different temperatures. Incorporation of nitrogen into the char was a result of incomplete removal of $\mathrm{IL}$ from the char, i.e., a portion of IL was difficult to recover due to a strong interaction with the char. The nitrogen content increased as the pyrolysis temperature increased and reached $1.6 \%$ at $350^{\circ} \mathrm{C}$, 75 accounting for $5.6 \mathrm{wt} \%$ of the IL used. Indeed, the recovery rate of IL from pyrolysis at $350^{\circ} \mathrm{C}$ was relatively low. Thus, to recover the $\mathrm{IL}$ with high purity as well as achieve a high yield of levoglucosenone, a temperature range of $250-300^{\circ} \mathrm{C}$ is recommended for the pyrolysis of cellulose/[BMMIM $] \mathrm{CF}_{3} \mathrm{SO}_{3}$.

\section{${ }_{80}$ Reaction pathway}

The reaction pathway for the formation of levoglucosenone from cellulose during pyrolysis of cellulose/BMMIM]CF $\mathrm{SO}_{3}$ is proposed in Fig. 4. This is based on a generally-accepted pathway in cellulose pyrolysis that proceeds via levoglucosan, and the ${ }_{85}$ formation of levoglucosenone from levoglucosan was 


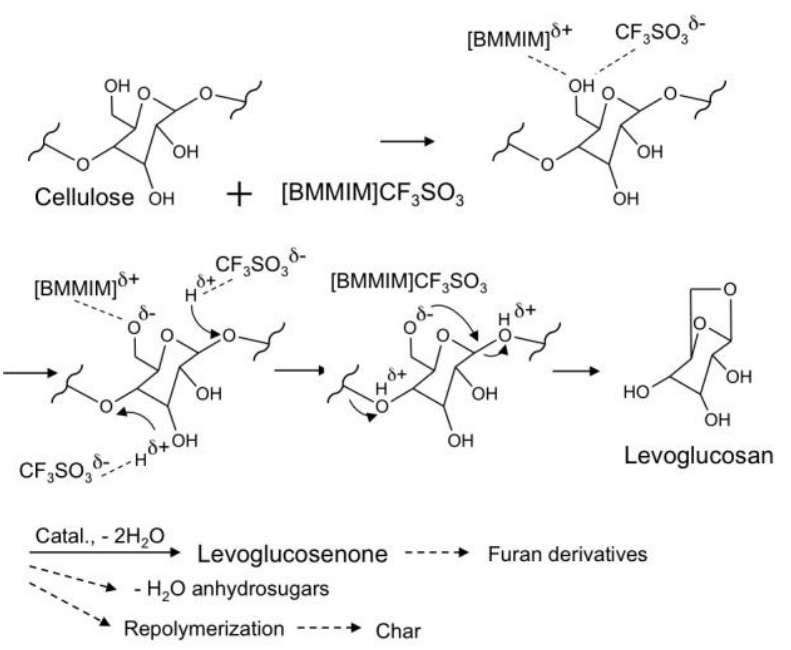

Fig. 4 Possible reaction pathway during the pyrolysis of cellulose/[BMMIM] $\mathrm{CF}_{3} \mathrm{SO}_{3}$.

experimentally demonstrated in the pyrolysis of 5 levoglucosan/[BMMIM] $\mathrm{CF}_{3} \mathrm{SO}_{3}$. Given this presumable reaction pathway, a very low content of levoglucosan in the product likely indicates that the one formed from cellulose was quickly converted to levoglucosenone by the catalysis of the IL. In other words, the conversion of cellulose to the intermediate, 10 levoglucosan, is a rate-controlling step and determine the production of levoglucosenone from this reaction pathway.

Because [BMMIM] $\mathrm{CF}_{3} \mathrm{SO}_{3}$ has no acidic proton, it is plausible that the protonation of the oxygen on the glycosidic bonds for bond cleavage is facilitated by the hydroxyl proton in the 15 cellulose. In the proposed reaction pathway, the catalysis of $[\mathrm{BMMIM}] \mathrm{CF}_{3} \mathrm{SO}_{3}$ is initiated by the formation of the electron donor-acceptor (EDA) complexes with a hydroxyl group at C6 position, followed by a shift of the hydroxyl proton onto the glycosidic bond using $\mathrm{CF}_{3} \mathrm{SO}_{3}{ }^{-}$as a carrier. It is known that the 20 EDA complexes between ILs and oxygen/hydrogen atoms of cellulose- $\mathrm{OH}$ contribute to the opening of hydrogen bonds between the cellulose molecules, resulting in dissolution of cellulose by ILs. ${ }^{28}$ Compared to $\mathrm{BF}_{4}^{-}$and $\mathrm{PF}_{6}^{-}$with a delocalized negative charge, $\mathrm{CF}_{3} \mathrm{SO}_{3}^{-}$is expected to have a stronger 25 interaction with the hydroxyl proton, resulting in the proposed catalytic effect.

Another plausible reaction pathway is a direct formation of levoglucosenone from cellulose, which was suggested by Kawamoto et al. ${ }^{16}$ in the analysis of products from the pyrolysis 30 of cellulose and levoglucosan using sulfolane and sulfuric acid as solvent and catalyst, respectively. Although the contribution of this mechanism to the formation of levoglucosenone is not clear from experimental data of this study, it is reasonable to explain the low yield of levoglucosan from the pyrolysis of 35 cellulose/[BMMIM $] \mathrm{CF}_{3} \mathrm{SO}_{3}$ by the direct formation of levoglucosenone. Fundamental roles of ILs for this reaction pathway are supposed to be same as proposed above, i.e., the cleavage of glycosidic bonds by carrying hydroxyl proton and the facilitation of dehydration reaction, but without liberation of 40 levoglucosan.

In the phosphoric acid-catalyzed method, phosphorylation and/or dehydration of cellulose at the C6 position extensively progress along with the catalysis to produce levoglucosenone.
Glucopyranose units, which underwent these reactions, are no ${ }_{45}$ longer decomposed to monosaccharides but condensed to char. ${ }^{29,30}$ On the other hand, the lower char yield in the pyrolysis of cellulose/[BMMIM] $\mathrm{CF}_{3} \mathrm{SO}_{3}$ demonstrated that the $\mathrm{IL}$ contributes little to reactions that promote charring, resulting in a high yield of levoglucosenone.

\section{${ }_{50}$ Conclusions}

In this study, pyrolysis of cellulose mixed with ILs as catalytic agent was conducted to obtain levoglucosenone. Results from TGA showed that ILs containing [BMMIM] as a cation possessed high thermal stability up to $300^{\circ} \mathrm{C}$, while only [BMMIM] $\mathrm{CF}_{3} \mathrm{SO}_{3}$ ${ }_{55}$ exhibited remarkable catalytic activity during low-temperature pyrolysis of cellulose. Product analysis showed that catalysis via $[\mathrm{BMMIM}] \mathrm{CF}_{3} \mathrm{SO}_{3}$ was selectively directed toward the splitting of the glycosidic bond and not toward the formation of char, leading to a high yield of levoglucosenone up to $22.0 \mathrm{wt} \%$ at ${ }_{60} 350^{\circ} \mathrm{C}$. Optimized pyrolysis conditions for reutilization of the IL were $25-50 \mathrm{wt} \%$ of IL in the mixture and pyrolysis temperatures between $250-300^{\circ} \mathrm{C}$ under the general experimental setup of this study. The work gave new insight into not only approach for the production of levoglucosenone, but also the utilization of ILs in ${ }_{65}$ the field of cellulose and/or biomass processing.

\section{Acknowledgements}

A part of this work was financially supported by Ministry of Education, Culture, Sports, Science and Technology (MEXT), Japan.

\section{${ }_{70}$ Notes and references}

${ }^{a}$ Institute for Materials Chemistry and Engineering, ${ }^{b}$ Research and

Education Center of Carbon Resources, Kyushu University, Kasuga, 8168580, Japan.E-mail: shinji_kudo@cm.kyushu-u.ac.jp;

Fax: +8192583 7793; Tel: +81925837793

1 Y.-C. Lin, J. Cho, G.A. Tompsett, P.R. Westmoreland, and G.W. Huber, J. Phys. Chem. C, 2009, 113, 20097.

2 D.K. Shen and S. Gu, Bioresource Technol., 2009, 100, 6496.

3 Z.J. Witczak, R. Chhabra, and J. Chojnacki, Tetrahedron Lett., 1997, $80 \quad 38,2215$.

4 A.M. Sarotti, R.A. Spanevello, C. Duhayon, J.-P. Tuchagues, and A.G. Suárez, Tetrahedron, 2007, 63, 241.

5 A.M. Sarotti, R.A. Spanevello, and A.G. Suárez, Tetrahedron, 2009, $\mathbf{6 5}, 3502$.

856 A.V. Samet, D.N. Lutov, S.I. Firgang, K.A. Lyssenko, and V.V. Semenov, Tetrahedron Lett., 2011, 52, 3026.

7 F. Shafizadeh and Y.L. Fu, Carbohyd. Res., 1973, 29, 113.

8 Y. Tsuchiya and K. Sumi, J. Appl. Polym. Sci., 1970, 14, 2003.

9 Y. Halpern, R. Riffer, and A. Broido, J. Org. Chem., 1973, 38, 204.

9010 G. Dobele, G. Rossinskaja, G. Telysheva, D. Meier, and O. Faix, $J$. Anal. Appl. Pyrolysis, 1999, 49, 307.

11 G. Dobele, D. Meier, O. Faix, S. Radtke, G. Rossinskaja, and G. Telysheva, J. Anal. Appl. Pyrolysis, 2001, 58-59, 453.

12 G. Dobele, T. Dizhbite, G. Rossinskaja, G. Telysheva, D. Meier, S 95 Radtke, and O. Faix, J. Anal. Appl. Pyrolysis, 2003, 68-69, 197.

13 Z. Wang, Q. Lu, X.-F. Zhu, and Y. Zhang, ChemSusChem, 2011, 4, 79 .

14 A.M. Sarotti, R.A. Spanevello, and A.G. Suárez, Green Chem., 2007, 9, 1137.

10015 H. Kawamoto, W. Hatanaka, and S. Saka, J. Anal. Appl. Pyrolysis, 2003, 70, 303. 
16 H. Kawamoto, S. Saito, W. Hatanaka, and S. Saka, J. Wood Sci., 2007, 53, 127.

17 H. Kawamoto, S. Saito, and S. Saka, Carbohyd. Res., 2008, 343, 249.

18 G.N. Sheldrake and D. Schleck, Green Chem., 2007, 9, 1044.

519 D.J. Nowakowski, C.R. Woodbridge, and J.M. Jones, J. Anal. Appl. Pyrolysis, 2008, 83, 197.

20 H. Olivier-Bourbigou, L. Magna, and D. Morvan, Appl. Catal. AGen., 2010, 373, 1.

21 R.P. Swatloski, S.K. Spear, J.D. Holbrey, and R.D. Rogers, J. Am. 10 Chem. Soc., 2002, 124, 4974.

22 J.B. Binder and R.T. Raines, J. Am. Chem. Soc., 2009, 131, 1979.
23 F. Jiang, Q. Zhu, D. Ma, X. Liu, and X. Han, J. Mol. Catal. A-Chem., 2011, 334, 8 .

24 F. Tao, H. Song, and L. Chou, Carbohyd. Res., 2011, 346, 58.

1525 J. Du, P. Liu, Z.-H. Liu, D.-G. Sun, and C.-Y. Tao, J. Fuel Chem. Technol., 2010, 38, 554.

26 P.A. Hunt, J. Phys. Chem. B, 2007, 111, 4844.

27 M.J. Muldoon, C.M. Gorson, and I.R. Dunkin, J. Chem. Soc., Perkin Trans., 2001, 2, 433.

2028 L. Feng and Z.-L. Chen, J. Mol. Liq., 2008, 142, 1.

29 K. Kishore and K. Mohandas, Fire Mater., 1982, 6, 54.

30 S. Gaan and G. Sun, J. Anal. Appl. Pyrolysis, 2007, 78, 371. 